\title{
System Reliability Calculation of Jacket Platforms Including Fatigue and Extreme Wave Loading
}

\author{
H. Khalili \\ NSIRC, Cambridge, United Kingdom \\ University of Strathclyde, Glasgow, United Kingdom
}

S. Oterkus \& N. Barltrop

University of Strathclyde, Glasgow, United Kingdom

U. Bharadwaj

TWI Ltd, Cambridge, United Kingdom

M. Tipping

Lloyd's Register, Southampton, United Kingdom

\begin{abstract}
Jacket platforms are redundant structures. Therefore, reliability analysis at system level is more applicable than at component level. Conventionally, system reliability analysis is estimated based on either fatigue loading or extreme environmental loading. The purpose of this study is to perform the structural reliability analysis of a jacket platform under both fatigue and extreme loading. In this study the fatigue limit state is defined based on the crack size, which is obtained by a fracture mechanics approach. The probability of failure for each component is calculated by using Monte-Carlo simulation. Important failure paths are identified by using a searching process. The system failure criterion is evaluated by comparing the platform strength and loading distributions in terms of base shear. In order to define a probabilistic formula for load, a global response surface method is adopted to relate the wave height to the response of the structure. A pushover analysis is also carried out to determine the capacity of the platform. Having calculated the structure strength and loading distributions, the annual probability of failure under extreme wave is calculated and compared to the tolerable probability of failure or target reliability. An application of the approach is presented.
\end{abstract}

Keywords: System reliability, fatigue failure, fracture mechanics, Monte-Carlo simulation, failure path, extreme wave loading, jacket platform

\section{INTRODUCTION}

Most studies in the offshore reliability analysis have been focusing on component reliability analysis over the years where a fatigue limit state or extreme wave limit state was considered to calculate the probability of failure (Aghakouchak \& Stiemer 2001, Rajasankar et al. 2003, Lin et al. 2012).

Offshore platforms are typically redundant structures and structural failure is a progressive process. A sequence of individual components is required to fail before overall failure occurs. Usually, there will be many possible sequences leading to collapse. Structural failure happens if one of these collapse sequences occurs. Therefore, it seems that system reliability is more important than component reliability for an offshore structure.

The calculation of the probability of a system failure has many theoretical and practical challenges. One of the difficulties with such calculation is that for typical structures, there are a very large number of sequences leading to failure and it is not practical to include all of them in the analysis (Karamchandani et al. 1991). However, only a few of these failure sequences have significant contributions to the total failure probability. Therefore, in the structural reliability analyses, a search technique should be considered to identify important failure sequences. The system failure event is then assumed as the union of these identified important sequences. Some studies have been performed to obtain the system reliability. The event formulation depends on the cause of failure. In previous structural systems reliability studies, two causes have been considered; fatigue loading and extreme environmental loading.

(Wang et al. 2006) considered fatigue failure as a common failure mode for offshore jacket platforms and calculated the system fatigue reliability for this type of structure. They proposed a new searching method for the system reliability analysis of structures to identify the dominant fatigue failure paths and evaluate the probability of system failure through failure paths. The main feature of their method was the system decomposition. The system decomposition was implemented by dividing the failure elements into two sub-systems according to the construction and fatigue failure characteristic of jacket structures. It was shown that system decomposition improved the calculation efficiency. (Marquez \& Sorensen 2013) studied system reliability for the offshore wind turbines regarding fatigue failure. They 
tried to find the important sequences of failure by utilising branch and bound technique and then they calculated system reliability through a combination of important failure paths leading to system failure.

Regarding extreme environmental load, (Kurian et al. 2014) performed the structural reliability of an existing jacket platform, by determining the system probability of failure. They used pushover analysis to determine possible failure paths of the structure under extreme wave loading. They established three failure paths of the platform under extreme wave loading and used simple bound formula to determine the failure probability.

In the above studies, only one failure mode was considered. Few studies have been performed that consider both fatigue and extreme wave loadings. (Karamchandani et al. 1991) considered a combination of fatigue and extreme loading. They presented a probabilistic formulation for a sequence of combined failures. However, they assumed the platform fails after only two component failures, which might not be a correct assumption. They concluded that for an individual member, the most probable cause of failure is fatigue, but for overall structural failure, overload and a combination of fatigue and overload are more important. (Oakley et al. 1992) proposed a simplified method of estimating system reliability of a structure. They considered both fatigue and extreme loading. The members were divided into groups, each group consisting of the diagonal bracings between any two levels of one frame. The structure was assumed to fail when any group failed. They compared the simplified method results with results from a rigorous analysis.

Due to shortcoming in the previous studies, in this study, a detailed approach is presented to calculate the probability of failure of a jacket platform under a combination of fatigue and extreme wave loads.

In this study, fatigue failure is considered at the component level and in establishing and identifying important failure paths. Extreme wave load failure is then, considered to check the system effect of the failure. For this purpose, the load and strength of the platform under extreme wave load are modelled as uncertain parameters. The extreme load is related to the 100-year wave height. Moreover, pushover analysis is used to determine the capacity of the platform.

\section{COMPONENT PROBABILITY OF FAILURE} Jacket platforms are likely to be fatigue damaged due to high-stress concentration and random cyclic wave loading. A fatigue crack starts at the weld toe at the hot spot location and gradually propagates around the intersection and through the tubular wall. Due to idealisations and approximations in the analysis process, fatigue analysis contains some uncertainties.

Two general approaches are widely used for fatigue analysis: S-N curve approach and fracture me- chanics (FM) approach. One of the significant shortcomings of the S-N method is that it cannot consider the changes in crack size during fatigue life. On the other hand, the FM approach relates the increase of crack size to the number of fatigue stress cycles and it is used to quantify the fatigue crack growth process (Almar-Naess 1985). The FM approach is also utilised to schedule the inspection strategy. In this study, fatigue reliability analysis is performed based on the FM approach.

\subsection{Fracture mechanics approach}

In the FM approach, the relationship between average increment in crack growth during a load cycle and a global parameter are developed. In this approach, the Paris law is used to describe the rate of fatigue crack growth:

$\mathrm{da} / \mathrm{dN}=\mathrm{C} \times(\Delta \mathrm{K})^{\mathrm{m}}$

Where a represents the crack size; $\mathrm{N}$ is the number of load cycles; $\Delta \mathrm{K}$ represents the stress intensity factor range; $\mathrm{C}$ and $\mathrm{m}$ are the material parameters. Stress intensity factor can be expressed as:

$\mathrm{K}=\mathrm{Y}(\mathrm{a}) \times \mathrm{S} \times \sqrt{\pi \mathrm{a}}$

Where $\mathrm{S}$ represents the stress due to applied load and $\mathrm{Y}(\mathrm{a})$ is the geometry function which depends on the crack geometry. There is no analytical solution for the geometry function for complex geometries such as tubular joints (Aghakouchak \& Stiemer 2001).

By integrating Equation 1 from initial crack size to the crack size at time $t$, the relation between crack size and number of cycles for the propagation of a crack can be obtained as:

$\int_{\mathrm{a}_{0}}^{\mathrm{a}_{\mathrm{t}}} \frac{\mathrm{da}}{(\mathrm{Y}(\mathrm{a}) \sqrt{\pi \mathrm{a}})^{\mathrm{m}}}=\mathrm{C} \times(\Delta \mathrm{S})^{\mathrm{m}} \times \mathrm{N}$

Where at represents the crack size at time $t$ after $\mathrm{N}$ cycles of loading and $\mathrm{a} 0$ is the initial crack size. Since the stress range is not constant in different load cycles; $(\Delta \mathrm{S})^{\mathrm{m}}$ can be replaced by $\mathrm{E}\left[\Delta \mathrm{S}^{\mathrm{m}}\right]$, which is the expected value (average) of stress range to the power $\mathrm{m}$. In Equation 3, fatigue stress range and number of the cycles should be determined. The sea wave loads during the platform service life are divided into a series of static sea states and each sea state can be described through the wave spectrum. If the stress is assumed as narrow banded and Rayleigh distributed (DNV report 1995), the equivalent fatigue stress of the $\mathrm{i}^{\text {th }}$ sea state can be represented as:

$\mathrm{E}\left[\Delta \mathrm{S}_{\mathrm{i}}^{\mathrm{m}}\right]=(2 \sqrt{2})^{\mathrm{m}} \times \sigma_{\mathrm{i}}^{\mathrm{m}} \times \Gamma\left(1+\frac{\mathrm{m}}{2}\right)$

Where $\Gamma$ is Gamma function and $\sigma_{\mathrm{i}}$ is standard deviation of the stress of the $\mathrm{i}^{\text {th }}$ sea state. Due to the existence of several sea states, the mean stress range to the power $\mathrm{m}$ is equal to summation of all sea state stress ranges to the power $m$ multiplied by the probability of occurrence (fraction of time) of each sea 
state. Moreover, the number of waves in each sea states is calculated as:

$\mathrm{N}_{\mathrm{i}}=\mathrm{T} \times \mathrm{v}_{0 \mathrm{i}}$

$\mathrm{T}$ is the time for which the crack size growth increment is calculated and $v_{0}$ i is zero mean crossing frequency of the stress process in the $i^{\text {th }}$ sea state (per year). By substituting Equation 4, 5 into Equation 3, crack size at time $t$ can be calculated as:

$\mathrm{a}_{\mathrm{t}}=\left\{\mathrm{a}_{0}^{1-\frac{\mathrm{m}}{2}}+\left(1-\frac{\mathrm{m}}{2}\right) \mathrm{Y}^{\mathrm{m}} \pi^{\frac{\mathrm{m}}{2}}\left[\mathrm{C} \times \mathrm{T}(2 \sqrt{2})^{\mathrm{m}} \Gamma\left(1+\frac{\mathrm{m}}{2}\right) \sum v_{0 \mathrm{i}} \sigma_{\mathrm{i}}^{\mathrm{m}} \mathrm{f}_{\mathrm{i}}\right]\right\}^{\frac{1}{1-\frac{\mathrm{m}}{2}}}(6)$

\subsection{Fatigue reliability analysis}

Due to the existence of uncertainties involved in quantifying the fatigue process, a reliability approach is adopted to assess the probability of failure. The probability of component failure is the probability that an initial crack grows beyond the critical crack size. By defining a fatigue limit state function and uncertainties involved in the fatigue process, the probability of failure can be obtained by using the MonteCarlo simulation method. In this study, (Rt software 2013) is used to perform Monte-Carlo simulation.

\subsubsection{Limit state function}

To evaluate the probability of failure, a failure event should be defined. Failure is usually defined based on the concept of a limit state, which represents a boundary between the safe and unsafe performance of a system or component (Dimitri 2014). In this study, the crack size is considered as the failure criterion for the component reliability analysis. It is assumed that failure occurs, as soon as the crack size is bigger than the critical value. Therefore, the fatigue limit state function is described as:

$g=a_{c}-a_{t}$

Where $a_{c}$ represents the critical crack size and $a_{t}$ is obtained from Equation 6. Critical crack size is often considered as the wall thickness (Wang et al. 2006). Failure occurs when $\mathrm{g}<0$.

\subsubsection{Fatigue uncertainties}

Several uncertainties exist during a fatigue process, in determining the stress range and in stress intensity factors. The reliability analysis depends on the choice of the uncertainties and their statistical distributions. Therefore, uncertainty modelling is very important for offshore reliability analysis. Due to the existence of these uncertainties, the calculated expected value of stress range is uncertain. For this purpose, $\varepsilon_{\mathrm{s}}$ and $\varepsilon_{S C F}$ are introduced to take into account the uncertainties involved in the calculation of actual stresses and those involved in computing stress concentration factors, respectively. Moreover, for considering the uncertainty in the calculation of the geometry function, $\varepsilon_{\mathrm{y}}$ is introduced.

\subsubsection{Reliability calculation}

There are several ways to calculate the reliability and the corresponding probability of failure, such as first order reliability method (FORM), second order reliability method (SORM) and simulation techniques. In the first two methods, transformations from the original distributions to corresponding equivalent normal distributions of uncertainties are needed (Dimitri 2014). In simulation technique methods, samples of the variables are generated and the relative number of samples corresponding to failure is used to estimate the probability of failure. The simulation techniques are different in the way the samples are generated.

In this study, Monte-Carlo simulation is used to obtain the probability of failure of each component.

\section{SYSTEM PROBABILITY OF FAILURE}

Reliability analysis at component level does not reflect the reliability of the system as a whole. For statistically determinate structures, the reliability of individual members is sufficient since the failure of one component will lead to the whole structure failure. However, for redundant structures such as jacket platforms, failure of one or a few members does not necessarily result in the collapse of the system (Kurian et al. 2014). A redundant structure is capable to redistribute forces even after the failure of one or more structural elements.

Calculation of the system reliability of redundant structures may be complex due to an enormous number of possible failure paths. A failure path is defined as the failure sequence of components in a structure until it totally collapses. It is practically impossible and not necessary to identify all possible failure paths. Therefore, identification of the dominant failure paths is one of the major tasks in the system reliability analysis for these structures (Kurian et al. 2014).

The system reliability analysis can be performed under either fatigue loading or extreme loading. For an individual component, the most probable cause of failure is fatigue, but for overall structural failure, a combination of fatigue and extreme loading is more critical. That means initial failures may occur in fatigue and subsequent collapse under an extreme wave. In this study, both fatigue and extreme wave failures are considered.

\subsection{Fatigue analysis}

Spectral fatigue analysis is used for dynamically sensitive structures in medium to deep water depths where non-linearity in the wave force such as drag and variable submergence are of limited importance (Manuel et al. 1998).

In spectral fatigue analysis, the major task is determination of the response of the structure to a unit sinusoidal wave as a function of wave frequency. This function is called the response transfer function. The 
transfer function is established by finding the stress range, at the location of interest, for a range of wave frequencies and dividing the results by the wave height. Transfer functions are obtained for each sea state. For each sea state, the sea surface elevation is characterised by the frequency spectrum. The response spectrum can be obtained as:

$\mathrm{S}_{\mathrm{ss}}(\omega)=\mathrm{S}_{\eta \eta}(\omega) \times|\mathrm{T}(\omega)|^{2}$

Where $\mathrm{S}_{\mathrm{ss}}(\omega)$ is the hot spot stress spectrum, $\mathrm{S}_{\eta \eta}(\omega)$ is water surface elevation spectrum, $\mathrm{T}(\omega)$ is transfer function and $\omega$ is the angular frequency of the wave. After obtaining the response spectrum, standard deviation and zero mean crossing frequency of the response of each sea state can be calculated as:

$\sigma=\sqrt{\mathrm{m}_{0}} ; \mathrm{v}_{0}=\sqrt{\frac{\mathrm{m}_{2}}{\mathrm{~m}_{0}}}$

Where $m_{0}$ and $m_{2}$ are spectral moments of stress spectrum. Having standard deviation and zero mean crossing frequency of the stress process for each sea state, the fatigue limit state function can be obtained using Equation 7.

\subsubsection{Dominant failure paths}

One of the difficulties in the calculation of system reliability is a large number of sequences leading to failure. It is not practical to include all of the sequences in the analysis. Usually, few of these failure sequences have significant contributions to the total failure probability. Therefore, in most structural reliability analyses, a searching process is used to identify important failure sequences.

There are different techniques to identify the dominant failure paths. Identification of the failure paths can be performed using Incremental Load Method, Branch and Bound Method and Truncated Enumeration Method. These methods have some shortcomings (Wang et al. 2006). For example, branch and bound method, although theoretically rigorous, is expensive for the analysis of structures with high redundancy, such as offshore jackets.

In this study, the sequence of structure joints most likely to fail is established using the branch and bound method. One of the advantages of this method is that it identifies sequences in decreasing order of importance.

As it was shown in Equation 6, the crack size of each component is expressed as a function of basic random variables. The sequence of failures occurs if each of these individual crack sizes reaches to critical crack size during the lifetime of the structure.

By performing component reliability analysis for the intact platform as the analysis basis, the joint with the highest fatigue failure probability is assumed to fail. This joint and corresponding member is then removed from the model and another spectral fatigue analysis is performed for this modified platform. Based on the new fatigue analysis results (spectral moments of the stress spectrum) the next probable joint to failure is obtained.

In this study, damage change ratio is a criterion for selection of the next probable joint to failure (Wang et al. 2006). The criterion states that only those joints, which have a large damage change ratio after the failure of the critical joint, are selected. Damage change ratio of joint $i$ after the failure of joint $j$ is defined as:

$r_{i j}=\frac{\left|D_{i}-D_{i / j}\right|}{D_{i}}$

Where $\mathrm{D}_{i}$ is the fatigue damage of a specific member before the $j^{\text {th }}$ joint failure, $D_{i / j}$ is the damage after the $\mathrm{j}^{\text {th }}$ joint failure. The change ratio of the damage of all the surviving elements is calculated. The failure paths are chosen based on the following criterion:

$\mathrm{r}_{\mathrm{ij}}>\alpha_{\mathrm{c}} \times \max \left(\mathrm{r}_{\mathrm{ij}}\right)$

Where $\alpha_{\mathrm{c}}$ is the selection ratio used to control the number of surviving elements. If $\alpha_{c}$ considered equal to zero, it means that all the surviving elements are included; if $\alpha_{c}$ assumed equal to one, only the surviving element with the highest change ratio of the damage rate is selected. In this study, $\alpha_{c}$ is considered equal to 0.7 .

\subsection{Extreme wave load analysis}

For performing extreme wave load analysis, the load and response of the structure should be modelled. The extreme load can be introduced by a random magnitude, which relates wave load to the extreme wave. In this study, the extreme wave is a wave corresponding to an annual exceedance probability of $10^{-2}(100$-year return period wave).

In this analysis, failure is assumed to occur by yielding at a section which is a function of axial force and the bending moment at the section. After the first failure, the force distribution in the structure changes, which leads to an increase in the stresses of the adjacent members of the failed member. The changes in the stress depend on the structure configuration, the location of the failed member and the post-failure behaviour of the failed member.

\subsubsection{Probability of failure under extreme load}

The extreme limit state can be written in terms of the base shear demand (load) that needs to be checked against the base shear capacity at collapse:

$\mathrm{g}_{\text {extreme }}=\mathrm{BS}_{\text {Capacity }}-\mathrm{BS}_{\text {Load }}$

In this equation, $\mathrm{BS}_{\text {Capacity }}$ and $\mathrm{BS}_{\mathrm{Load}}$ are random variables that refer to the base shear capacity and demand, respectively. The platform fails when the exerted load is greater than platform capacity. Therefore, the extreme probability of failure is the probability of $g_{\text {extreme }}$ being less than zero:

$\mathrm{P}_{\mathrm{f}}=\mathrm{P}\left(\mathrm{g}_{\text {extreme }}<0\right)=\mathrm{P}\left(\mathrm{BS}_{\text {Capacity }}<\mathrm{BS}_{\text {Load }}\right)$ 
By calculation of base shear capacity and base shear load, the probability of failure for the extreme load can be obtained by using Monte-Carlo simulation.

\subsubsection{Global response surface}

The global response surface relates the environmental load (BSLoad) to the extreme wave height (Rabi 1991):

$\mathrm{BS}_{\text {Load }}=\Gamma \times\left(\mathrm{cH}_{\max }^{\alpha}\right)$

Here, $\mathrm{c}$ and $\alpha$ are deterministic constants describing how the load varies with wave height. In order to determine the response of the structure, different sets of wave heights are generated based on wave height distribution and structural analysis is carried out. From the analysis, load results are obtained. The coefficients $\mathrm{c}$ and $\alpha$ are determined using fitting tools.

The parameter, $\Gamma$, is a factor representing the uncertainty involved in estimating load from wave height when deterministic amounts for $\mathrm{c}$ and $\alpha$ are used. $\Gamma$ is modelled as a lognormal random variable with a mean equal to 1.0 and coefficient of variation (COV) equal to 0.25 (Manuel et al. 1998).

\subsubsection{Platform capacity}

The capacity of the structure can be determined by pushover analysis. This analysis provides an insight into the load bearing performance of the platform, indicates the failure modes and the post-failure behaviour of the structure. The procedure adopted for the pushover analysis consists of the extreme wave load, which is incrementally introduced to the platform. The environmental load is gradually increased to induce member yielding or buckling and to eventually lead to the global collapse in the platform.

The structure has a random capacity (BSCapacity) which is the largest load the structure can withstand without system failure. In this study, the base shear capacity is assumed as a lognormal random variable. A COV of $15-20 \%$ is consistent for the capacity of jacket platforms (Manuel et al. 1998). In this study, the COV for capacity is considered equal to 0.20 .

\subsubsection{System failure criteria}

The common criterion of system failure is a major loss of the global stiffness. The global stiffness is measured by the increase in deflection at the centre of the deck due to a unit increase in load. It is observed that usually, there is little change in stiffness during the first few member failures but after the failure of several members, a large change in stiffness often occurred. This large change in stiffness is used to detect system failure (Manuel et al. 1998).

The other criterion for system failure could be using of target reliability levels in design codes. Several codes and standards such as Eurocode and DNV introduce target reliability levels for the different type of platforms. For example, target annual reliability for a redundant structure with the high consequence of failure is equal to $10^{-4}$ in the DNV report (2018). Therefore, in this study, a target probability of failure $\mathrm{P}_{\mathrm{T}}$ equal to $10^{-4}$ per year is used.

After removing each failed component in the failure path, the annual probability of failure of the platform under extreme wave condition (given fatigue failure has happened), is compared with the target probability of failure.

If the probability that the structure no longer satisfies strength requirements $\left(\left(\mathrm{P}_{\mathrm{f}}\right)_{\text {Annual }}\right.$ in Equation 15), is less than $\mathrm{P}_{\mathrm{T}}$, the platform is considered as a safe system. A failure path is deemed as completed when $\left(\mathrm{P}_{\mathrm{f}}\right)$ Annual is greater than $\mathrm{P}_{\mathrm{T}}$.

$\left(\mathrm{P}_{\mathrm{f}}\right)_{\text {Annual }}>\mathrm{P}_{\mathrm{T}}$

\subsection{System probability of failure}

To calculate system probability of failure under both fatigue and extreme wave load, the conditional probability of extreme loads can be used. These conditional probabilities are multiplied by the probability of fatigue failures, and (for low failure probabilities) the products are summed to obtain the system probability of failure. Therefore, the probability of failure of a platform under an extreme wave and fatigue loading can be obtained based on:

$\mathrm{P}($ Ext $)=\sum_{\mathrm{k}=0}^{\mathrm{n}} \mathrm{P}\left(\right.$ Ext $\left.\cap \mathrm{F}_{\mathrm{k}}\right)=\sum_{\mathrm{k}=0}^{\mathrm{n}} \mathrm{P}\left(\mathrm{F}_{\mathrm{k}}\right) \times \mathrm{P}\left(\right.$ Ext $\left.\mid \mathrm{F}_{\mathrm{k}}\right)$

Where $\mathrm{P}\left(\mathrm{F}_{\mathrm{k}}\right)$ is the probability of failure of " $\mathrm{k}$ " joints in fatigue loading; e.g. $F_{0}$ is an event in which no component fails in fatigue (Intact case); $\mathrm{F}_{1}$ is an event in which only one component fails in fatigue, etc. Moreover, "Ext" is an event in which platform fails under an extreme wave and $\mathrm{P}\left(\mathrm{Ext} \mid \mathrm{F}_{\mathrm{k}}\right)$ is the probability of failure under extreme loading given that " $k$ " joints failed in fatigue.

Here, the probability of failure for each fatigue failure case $\left(\mathrm{F}_{0}, \mathrm{~F}_{1}\right.$, etc. $)$, is obtained based MonteCarlo simulation (by using fatigue limit state function). The conditional probability, $\mathrm{P}\left(\mathrm{Ext} \mid \mathrm{F}_{\mathrm{k}}\right)$, is calculated based on extreme limit state function. Total probability of system failure over the entire range of fatigue failure is computed using Equation 16.

\section{APPLICATION OF APPROACH}

To apply the methodology described in this study, a jacket platform is considered. The example structure is a four-legged living quarter platform which located in a water depth of $70 \mathrm{~m}$. The choice of this platform is motivated by the degree of structural redundancy, which is believed to be typical for this specific area. Figure 1 shows the flowchart of the proposed approach for a jacket platform. 


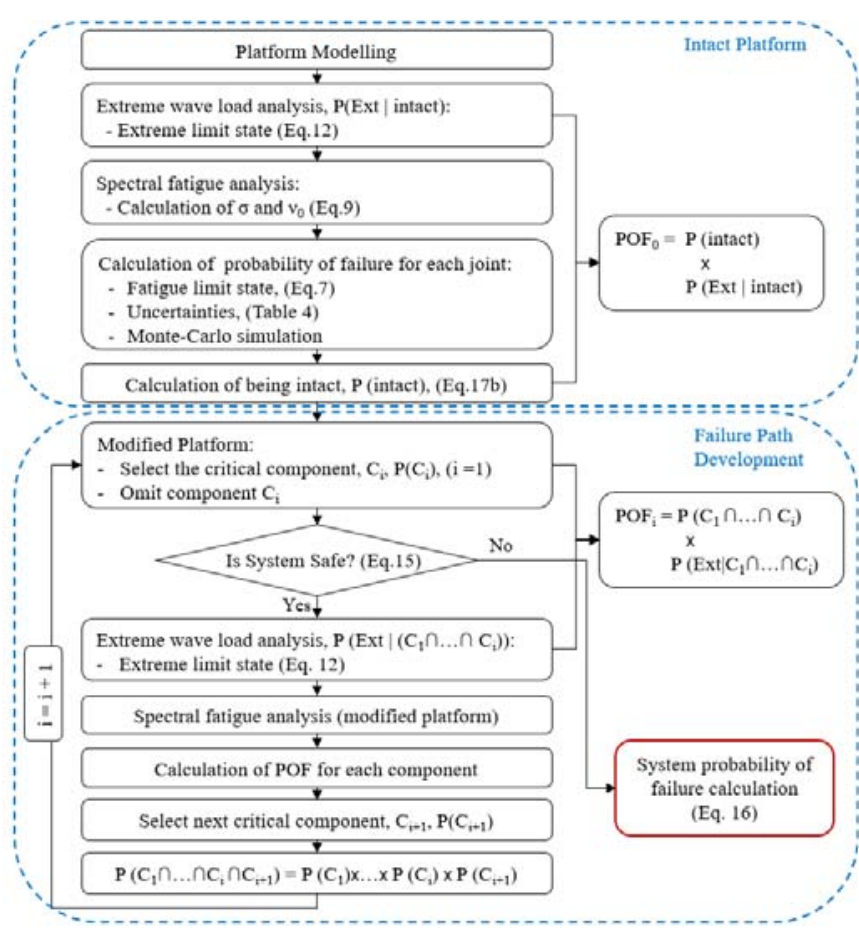

Figure 1. Flowchart of the proposed approach for jacket platform

\subsection{Intact platform}

A three-dimensional structural model of the platform is generated using SESAM software (2015). The model incorporates all primary members and all gravitational and environmental loads. The main characteristic of the jacket platform is given in Table 1.

Table 1. Main characteristics of the considered jacket

\begin{tabular}{ll}
\hline \multicolumn{1}{c}{ Item } & \multicolumn{1}{c}{ Description } \\
\hline Platform function & Living quarter \\
Bracing type & X-Bracing \\
Topside gravity load & $27.8 \mathrm{MN}$ \\
Maximum 100-year wave load & $3.2 \mathrm{MN}$ \\
\hline
\end{tabular}

\subsubsection{Extreme wave load analysis}

Monte-Carlo simulation is employed to calculate the probability of failure under extreme load in intact case $(\mathrm{P}($ Ext $\mid$ intact $))$. For this purpose an extreme limit state function is used.

In order to obtain BScapacity, pushover analysis is performed. To carry out the pushover analysis, USFOS software is employed (2015). USFOS is a finite element program specifically developed for estimating the ultimate strength of space frame structures and identifying the collapse mechanisms. The software performs non-linear collapse analysis, in which, the structure and members are incrementally loaded beyond their yielding capacity. Based on the USFOS analysis results, the collapse base shear (BS Capacity $_{\text {) of }}$ this platform (in intact case) is equal to $13.1 \mathrm{MN}$.

For calculation of load (BS $\left.\mathrm{B}_{\text {Load }}\right)$, forty sets of wave loads are generated based on wave height distribution and structural analysis is then carried out. From the analysis, forty sets of base shears are obtained. In this study, a Gumbel distribution with $\mu=12.0$ and scale parameter $(\beta)$ of 1.2 is considered for wave height distribution (Fayyazi \& Aghakouchak 2014).

Using simulated data from the distribution of wave height and corresponding base shears (obtained from SESAM), $\mathrm{c}$ and $\alpha$ are estimated as $\mathrm{c}=0.035$ and $\alpha=$ 1.93. Table 2 shows the characteristics of random variables in extreme wave load analysis in the intact case.

Table 2. Characteristics of variables in extreme analysis

\begin{tabular}{llll}
\hline \hline Variable & Type & \multicolumn{1}{c}{ Mean } & COV \\
\hline BS $_{\text {Capacity }}$ & Lognormal & $13.1 \mathrm{MN}$ & 0.20 \\
$\mathrm{H}_{\max }$ & Gumbel & $\mu=12.0, \beta=1.2$ & --- \\
$\Gamma$ & Lognormal & 1.0 & 0.25 \\
\hline
\end{tabular}

Using above variables and extreme limit state function, by performing Monte-Carlo simulation by using Rt software (2013), the probability of failure of the platform under extreme wave loading in the intact case $(\mathrm{P}($ Ext $\mid$ intact $))$ is obtained equal to $4 \times 10^{-5}$.

\subsubsection{Spectral fatigue analysis}

A spectral fatigue analysis for the modelled platform is performed using SESAM software (2015). The stress parameters are computed using a frequency domain approach. The environment is modelled in terms of a set of stationary sea states, in which each sea state is characterised by a significant wave height, a mean zero crossing period and a direction. The probabilities of occurrence of the sea states are usually obtained by measurement and summarised as a wave scatter diagram. In each sea state, a Pierson-Moskowitz wave spectrum is assumed. Table 3 shows the characteristics of the sea states approaching from the north-west direction.

For each component and wave direction, SESAM computes transfer functions and spectral moments. Having obtained the spectral moments, the standard deviation and zero mean crossing frequency of the stress for each sea state can be calculated. Table 3 shows the results of fatigue analysis in terms of the stress spectrum for one specific wave direction.

Table 3. Characteristics of sea states and stress spectrum results

\begin{tabular}{ccccc}
\hline $\mathrm{H}_{\mathrm{s}}(\mathrm{m})$ & $\mathrm{T}_{\mathrm{z}}(\mathrm{sec})$ & Fraction, $\mathrm{f}_{\mathrm{i}}$ & $\sigma(\mathrm{MPa})$ & $v_{0}$ \\
\hline 2.75 & 6.5 & 0.0019 & 22.57 & 0.17 \\
2.75 & 7.5 & 0.0265 & 20.83 & 0.16 \\
2.75 & 8.5 & 0.0054 & 19.45 & 0.14 \\
3.25 & 7.5 & 0.0060 & 24.62 & 0.16 \\
3.25 & 8.5 & 0.0123 & 22.98 & 0.14 \\
3.75 & 7.5 & 0.0001 & 28.41 & 0.16 \\
3.75 & 8.5 & 0.0087 & 26.52 & 0.14 \\
3.75 & 9.5 & 0.0009 & 24.97 & 0.13 \\
4.25 & 8.5 & 0.0013 & 30.05 & 0.14 \\
4.25 & 9.5 & 0.0019 & 28.30 & 0.13 \\
4.75 & 9.5 & 0.0006 & 31.63 & 0.13 \\
\hline
\end{tabular}


4.1.3 Calculation of component probability of failure

Now, the probability of failure of each component is obtained using Monte-Carlo simulation. It was mentioned that for performing Monte-Carlo simulation, the fatigue limit state function and fatigue uncertainties should be defined. The fatigue limit state function was already introduced as Equation 7. Table 4 represents the uncertainties, which are considered in this study.

Table 4. Characteristics of random variables, Units [N, mm]

\begin{tabular}{llll}
\hline \multicolumn{1}{c}{ Variable } & Type & Mean & COV \\
\hline Critical crack size, $\mathrm{a}_{\mathrm{c}}$ & Fixed & \multicolumn{2}{l}{ Thickness } \\
Initial crack size, $\mathrm{a}_{0}$ & Exponential & 0.11 & 1.0 \\
Material properties, ln C & Normal & -31.01 & 0.014 \\
Material properties, $\mathrm{m}$ & Fixed & 3 & ---- \\
Errors in $\mathrm{Y}(\mathrm{a}), \varepsilon_{\mathrm{y}}$ & Lognormal & 1.0 & 0.1 \\
Errors in stresses, $\varepsilon_{\mathrm{s}}$ & Normal & 1.0 & 0.05 \\
Errors in SCFs, $\varepsilon_{\mathrm{SCF}}$ & Lognormal & 1.0 & 0.05 \\
\hline
\end{tabular}

After performing Monte-Carlo simulation, the probability of failure for each joint is obtained. Table 5 demonstrates the probability of failure for the five most critical components in this platform.

Table 5. Fatigue probability of failure for critical components

\begin{tabular}{lcc}
\hline Component & $\sum v_{0 \mathrm{i}} \times \sigma_{\mathrm{i}}^{\mathrm{m}_{\mathrm{i}}} \times \mathrm{f}_{\mathrm{i}}$ & Probability of Failure \\
\hline BM36-Jt3 & 317.4 & 0.022 \\
BM12-Jt3 & 303.6 & 0.018 \\
BM34-Jt14 & 270.8 & 0.0100 \\
BM24-Jt14 & 258.6 & 0.0079 \\
BM35-Jt4 & 214.2 & 0.0026 \\
\hline
\end{tabular}

Figure 2 shows the location of critical components in fatigue analysis.

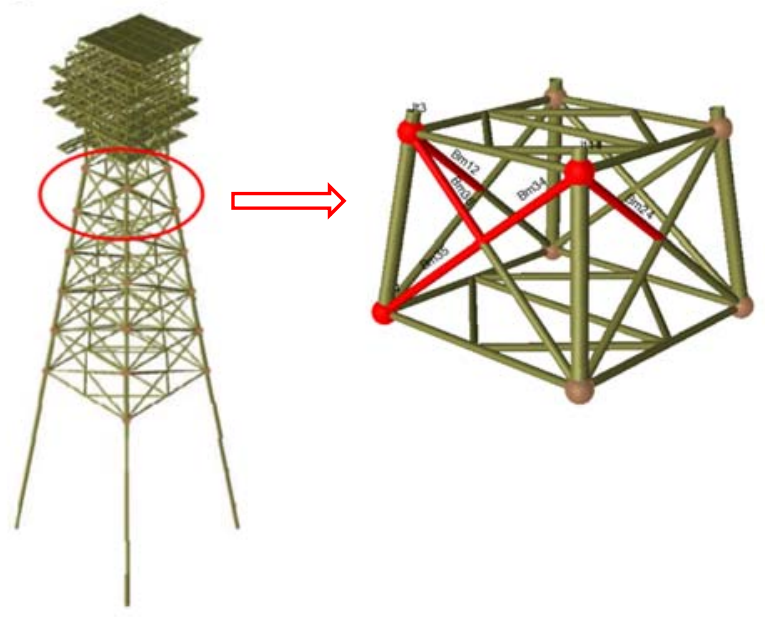

Figure 2. Location of critical components in fatigue analysis

The platform is intact when all components are safe in fatigue. It means that no component $\left(\mathrm{C}_{\mathrm{i}}\right)$ fails in fatigue loading. Therefore, the probability of being intact is:

$\mathrm{P}($ intact $)=\mathrm{P}\left(\mathrm{C}_{1}\right.$ is safe $) \cap\left(\mathrm{C}_{2}\right.$ is safe $) \cap \ldots \cap\left(\mathrm{C}_{\mathrm{n}}\right.$ is safe $) \quad(17 \mathrm{a})$
$\mathrm{P}($ intact $)=\left(1-\mathrm{P}_{1}\right) \times\left(1-\mathrm{P}_{2}\right) \times \ldots \times\left(1-\mathrm{P}_{\mathrm{n}}\right)=\prod_{\mathrm{i}=1}^{\mathrm{n}}\left(1-\mathrm{P}_{\mathrm{i}}\right)$

In which, $P_{i}$ is the probability of failure of the $i^{\text {th }}$ component in fatigue. Having the $\mathrm{P}$ (intact), the probability of failure under both extreme wave load and fatigue load (intact case) can be calculated as:

$\mathrm{POF}_{0}=\mathrm{P}($ intact $) \times \mathrm{P}($ Ext $\mid$ intact $)$

\subsection{Failure path development}

Based on Table 5, the most critical component (BM36-Jt3) is selected as the first component in the failure path. The modified platform is a platform in which this component $\left(\mathrm{C}_{\mathrm{i}}\right)$ has been removed.

\subsubsection{Check system safety}

After removing the critical component, system failure criteria should be checked based on Equation 15. If the platform fails, the system probability of failure is obtained based on Equation 16. Otherwise, the following process is continued which includes:

\section{Extreme wave analysis (modified platform)}

In this step, another extreme wave analysis is performed for the modified platform (platform without component BM36-Jt3) in USFOS software. The same process as section 4.1.2 is repeated for calculation of the probability of failure. The difference here is that due to removing one specific component, BSCapacity in this step $(12.95 \mathrm{MN})$ is less than the previous amount of BSCapacity in intact case $(13.1 \mathrm{MN})$. In general, the platform capacity decreases when the number of failed components in fatigue increases. Therefore, the conditional probability of failure increases by increasing the number of failed components in fatigue (i.e. $\left.\mathrm{P}\left(\mathrm{Ext}_{\mid} \mathrm{C}_{1} \cap \ldots \cap \mathrm{C}_{\mathrm{n}+1}\right)>\mathrm{P}\left(\mathrm{Ext}_{\mid} \mid \mathrm{C}_{1} \cap \ldots \cap \mathrm{C}_{n}\right)\right)$. Figure 3 shows the probability distributions for load and capacity in intact and two damaged cases.

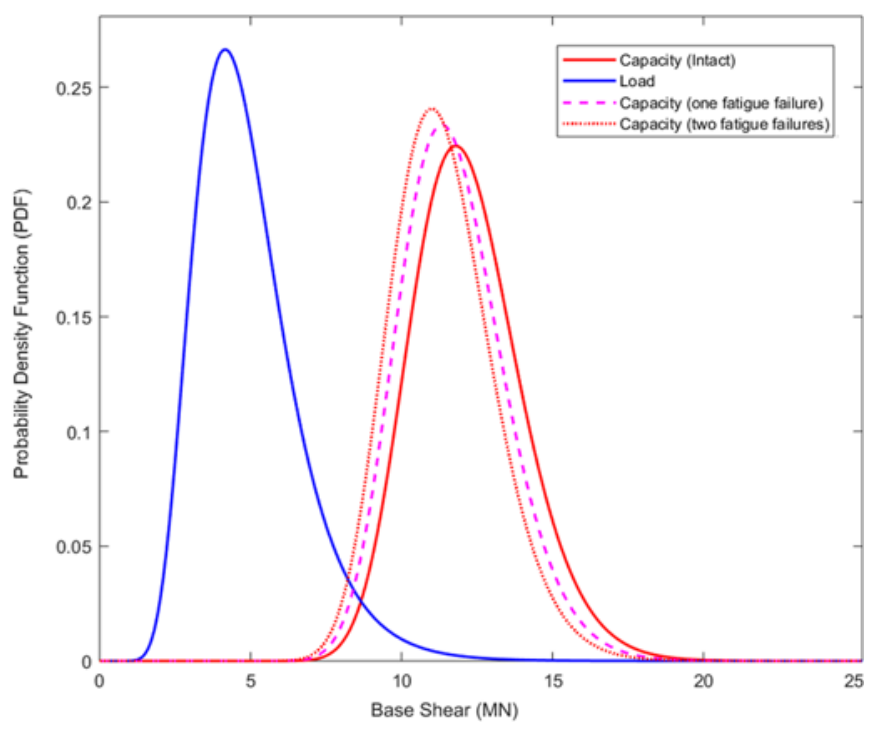

Figure 3. Probability density function for load and capacity

Monte-Carlo simulation is again performed and the probability of failure under extreme load given 
one component failure in fatigue is obtained $(\mathrm{P}(\mathrm{Ext}$ $\left.\left.\mathrm{C}_{1}\right)\right)$. Having calculated the $\mathrm{P}\left(\operatorname{Ext} \mid \mathrm{C}_{1}\right)$, the probability of failure under both extreme wave load and fatigue load (the case in which only one component fails in fatigue) can be calculated as:

$\mathrm{POF}_{1}=\mathrm{P}\left(\mathrm{C}_{1}\right) \times \mathrm{P}\left(\mathrm{Ext} \mid \mathrm{C}_{1}\right)$

\section{Spectral fatigue analysis (modified platform)}

The next step is finding the next critical component in the failure path. For this purpose, another fatigue analysis is carried out (for the modified platform). The results of the spectral fatigue analysis are standard deviation and zero mean crossing frequency of the stress for each sea state. Then, the probability of failure for each component is obtained by using Monte Carlo simulation. Based on the selection criterion, the next critical component in the failure path $\left(\mathrm{C}_{\mathrm{i}+1}\right)$ is selected.

\subsection{System probability of failure calculation}

A platform with probability exceeds the threshold given by Equation 15 is considered as a failed platform. Failure of a platform under an extreme wave and fatigue loading can be obtained based on Equation 16 which can be written as:

$$
\begin{aligned}
\mathrm{P}(\text { Ext })= & \mathrm{P}(\text { intact }) \times \mathrm{P}(\text { Ext } \mid \text { intact })+\mathrm{P}\left(\mathrm{C}_{1}\right) \times \mathrm{P}\left(\text { Ext } \mid \mathrm{C}_{1}\right) \\
& +\mathrm{P}\left(\mathrm{C}_{1} \cap \mathrm{C}_{2}\right) \times \mathrm{P}\left(\text { Ext } \mathrm{C}_{1} \cap \mathrm{C}_{2}\right)+\ldots \\
& +\mathrm{P}\left(\mathrm{C}_{1} \cap \mathrm{C}_{2} \cap \ldots \cap \mathrm{C}_{\mathrm{n}}\right) \times \mathrm{P}\left(\text { Ext } \mathrm{C}_{1} \cap \mathrm{C}_{2} \cap \ldots \cap \mathrm{C}_{\mathrm{n}}\right)
\end{aligned}
$$

Which above probabilities have been already obtained using Equations 18-19. In this equation, $\mathrm{n}$ is the number of components, which failed before the system failure. As shown in Figure 4, for the first, second and forth failure paths $\mathrm{n}$ is equal to six, whereas, for the third failure path, $n$ is equal to four.

Note that, for each failure path, the last probability, $\mathrm{P}\left(\right.$ Ext $\left.\mid \mathrm{C}_{1} \cap \mathrm{C}_{2} \cap \ldots \cap \mathrm{C}_{\mathrm{n}}\right)$ is greater than target probability failure $\left(\mathrm{PT}_{\mathrm{T}}\right)$ as shown in Figure 4.

The described methodology in Section 4.1 to 4.3 is a procedure to calculate the probability of failure of one specific path. In order to calculate the total probability of failure, a complete failure tree should be produced based on the sequence of the failures and the probability of failure of all failure paths. The important sequences of failure scenario are found using the branch tree. The branch tree is established through the failure probability determined for the fatigue failure mode. Figure 4 shows the important failure sequences identified through branch tree. Each branch represents a possible failure path, and each node is the failed component.

The probability of failure for all failure paths should be calculated. Table 6 illustrates the summary of results for the first failure path.

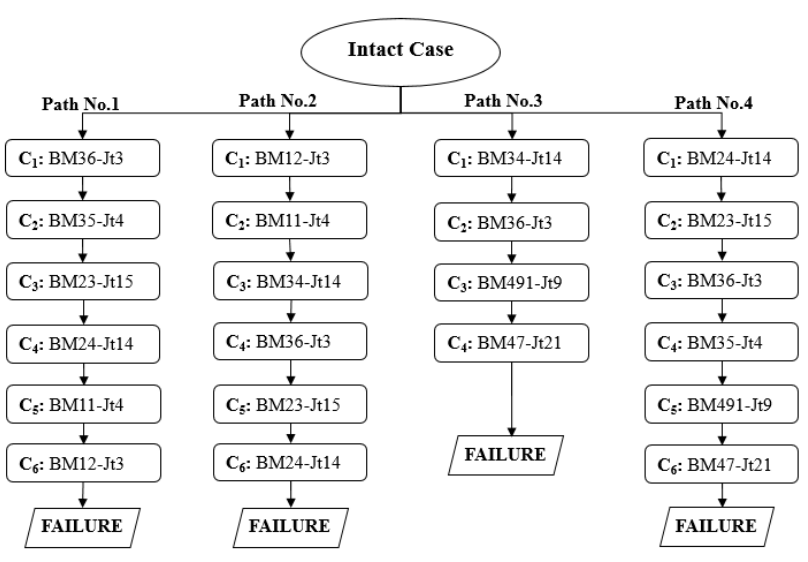

\begin{tabular}{|c|c|c|c|}
\hline Sequence & $\mathrm{P}\left(\mathrm{C}_{1} \cap \ldots \cap \mathrm{C}_{\mathrm{i}}\right)$ & $\left(\mathrm{Ext} \mid \mathrm{C}_{1} \cap \ldots \cap \mathrm{C}_{\mathrm{i}}\right.$ & $\mathrm{POF}_{\mathrm{i}}$ \\
\hline $\begin{array}{l}\text { No failure } \\
\text { (Intact) }\end{array}$ & $\mathrm{P}($ intact $)=0.934$ & $4 \times 10^{-5}$ & $3.74 \times 10^{-5}$ \\
\hline $\begin{array}{l}1^{\text {st }} \text { failure } \\
\mathrm{C}_{1}: \mathrm{BM} 36-\mathrm{Jt} 3\end{array}$ & $\mathrm{P}\left(\mathrm{C}_{1}\right)=0.022$ & $5 \times 10^{-5}$ & $1.1 \times 10^{-6}$ \\
\hline $\begin{array}{l}2^{\text {nd }} \text { failure } \\
\mathrm{C}_{2}: \mathrm{BM} 35-\mathrm{Jt} 4\end{array}$ & $\begin{array}{l}\mathrm{P}\left(\mathrm{C}_{1} \cap \mathrm{C}_{2}\right)=0.022 \\
\left(\min \left[\mathrm{P}\left(\mathrm{C}_{1}\right), \mathrm{P}\left(\mathrm{C}_{2}\right)\right]\right)\end{array}$ & $6.2 \times 10^{-5}$ & $1.4 \times 10^{-6}$ \\
\hline $\begin{array}{l}3^{\text {rd }} \text { failure } \\
\mathrm{C}_{3}: \mathrm{BM} 23-\mathrm{Jt} 15\end{array}$ & $\begin{array}{l}\mathrm{P}\left(\mathrm{C}_{1} \cap \ldots \cap \mathrm{C}_{3}\right)=0.001 \\
\left(=\min \left[\mathrm{P}\left(\mathrm{C}_{1}\right) \ldots, \mathrm{P}\left(\mathrm{C}_{3}\right)\right]\right)\end{array}$ & $7 \times 10^{-5}$ & $7 \times 10^{-8}$ \\
\hline $\begin{array}{l}4^{\text {th }} \text { failure } \\
\mathrm{C}_{4}: \mathrm{BM} 24-\mathrm{Jt} 14\end{array}$ & $\begin{array}{l}\mathrm{P}\left(\mathrm{C}_{1} \cap \ldots \cap \mathrm{C}_{4}\right)=0.001 \\
\left(=\min \left[\mathrm{P}\left(\mathrm{C}_{1}\right) \ldots, \mathrm{P}\left(\mathrm{C}_{4}\right)\right]\right)\end{array}$ & $7.7 \times 10^{-5}$ & $7.7 \times 10^{-8}$ \\
\hline $\begin{array}{l}5^{\text {th }} \text { failure } \\
\mathrm{C}_{5}: \mathrm{BM} 11-\mathrm{Jt} 4\end{array}$ & $\begin{array}{l}\mathrm{P}\left(\mathrm{C}_{1} \cap \ldots \cap \mathrm{C}_{5}\right)=0.001 \\
\left(=\min \left[\mathrm{P}\left(\mathrm{C}_{1}\right) \ldots, \mathrm{P}\left(\mathrm{C}_{5}\right)\right]\right)\end{array}$ & $8.8 \times 10^{-5}$ & $8.8 \times 10^{-8}$ \\
\hline $\begin{array}{l}6^{\text {th }} \text { failure } \\
\text { C6:BM12-Jt3 }^{\text {B B }}\end{array}$ & $\begin{array}{l}\mathrm{P}\left(\mathrm{C}_{1} \cap \ldots \cap \mathrm{C}_{6}\right)=0.001 \\
\left(=\min \left[\mathrm{P}\left(\mathrm{C}_{1}\right), \ldots, \mathrm{P}\left(\mathrm{C}_{6}\right)\right]\right)\end{array}$ & $10.5 \times 10^{-5}$ & $1.1 \times 10^{-7}$ \\
\hline \multicolumn{3}{|c|}{$\mathrm{P}(\mathrm{Ext})=\mathrm{POF}_{0}+\mathrm{POF}_{1}+\mathrm{POF}_{2}+\ldots+\mathrm{POF}_{6}=$} & $4.03 \times 10^{-5}$ \\
\hline
\end{tabular}

Figure 4. Failure path obtained for fatigue failure

Table 6. System probability of failure of the first failure path

In terms of series and parallel systems, the sequence leading to structural collapse forms the parallel system and the combination of all these sequences represents the series system (the structural system is a series of parallel systems, in which each parallel system represents a failure path). The system probability of failure is then determined from the probability of failures using the Simple Bound formula for series systems. The upper and lower bound of the probability of failure is given as:

$\max _{j}\left(P_{j}(E x t)\right) \leq P_{\text {System }}($ Ext $) \leq 1-\prod_{j}\left(1-P_{j}(\right.$ Ext $\left.)\right)$

Where Psystem(Ext) is the system probability of failure and $P_{j}(E x t)$ represents the probability of failure of path $\mathrm{j}$. The lower bound is the probability of failure for fully correlated paths and the upper bound is the probability of failure when all paths are uncorrelated.

Considering $\mathrm{P}_{\mathrm{j}}(\mathrm{Ext})$ results for all four failure paths and using Equation 21, the probability of failure of the jacket platform is between: 


$$
4.21 \times 10^{-5} \leq \mathrm{P}_{\text {System }}(\text { Ext }) \leq 16.4 \times 10^{-5}
$$

Due to the existence of a correlation between these failure paths, it seems that the probability of failure of this platform is close to the lower bound of the probability of failure. Results of system reliability analysis show that although the probability of failure of some joints in fatigue is relatively high, regarding the high redundancy level in this platform, the system probability of failure is much lower than the component probability of failure.

\section{CONCLUSION}

Due to the high redundancy of offshore jacket platform, the probability of failure of the whole system is more applicable than the component probability of failure. Therefore, in this study, the failure probability of the structural system in the combination of fatigue and extreme wave load was calculated. For this purpose, four significant failure sequences were identified in the branch tree leading to structural collapse. By removing the members, which failed in fatigue, the probability of failure of the structure under extreme wave loading increases. When the probability that the structure no longer satisfies strength requirements exceeds the target probability of failure, the platform is assumed to fail. Finally, the probability of failure of the system is estimated using the simple bounds formula.

\section{ACKNOWLEDGEMENT}

This study was made possible by the sponsorship and support of Lloyd's Register Foundation. The Foundation helps to protect life and property by supporting engineering-related education, public engagement and the application of research. The work was enabled through, the National Structural Integrity Research Centre (NSIRC), a postgraduate engineering facility for industry-led research into structural integrity. NSIRC was established and is managed by TWI through a network of both national and international universities and industry. For the purpose of this research, the University of Strathclyde, Lloyd's Register Foundation and TWI Ltd collaborated under the auspices of NSIRC.

\section{REFERENCES}

Aghakouchak, A.A \& Stiemer, S.F. 2001. Fatigue reliability assessment of tubular joints of existing offshore structures, $\mathrm{Ca}$ nadian Journal of civil engineering, Vol. 28

Rajasankar, J. \& Iyer, N.R \& AppaRoa, T. 2003. Structural integrity assessment of offshore tubular joints based on reliability analysis, International Journal of Fatigue, Vol. 25

Lin, H. \& Chen, G. \& Wang, Z. \& Yang, L. 2012. Integrity assessment of tubular joints in ageing offshore platform based on reliability theory, advanced material research, Vol. 532
Karamchandani, A. \& Dalane, J. \& Bjerager, P. 1991. Systems reliability of offshore structures including fatigue and extreme wave loading, marine structure, Vol. 4

Wang, W. \& Shi, Y. \& Wang, C. \& Li, S. 2006. A new method for system fatigue reliability analysis of offshore steel jacket, Advances in Structural Engineering, Vol. 9

Marquez, S. \& Sorensen, J. 2013. System reliability for offshore wind turbines: fatigue failure, $O M A E$

Kurian, V. \& Wahab, M. \& Kheang, T \& Liew, M. 2014. System reliability of existing jacket platform in Malaysian water, Applied Mechanics and materials, Vol. 567

Oakley, A. \& Brown, M. \& Warren, P. \& Barltrop, N. 1992. Optimised inspection scheduling for offshore structures, a probabilistic approach

Almar-Naess, A. 1985. Fatigue handbook for offshore steel structures, Tapir publication

Dimitri Val. 2014. Safety, risk and reliability, Heriot-Watt University

DNV report No. 95-3203. 1995. Guideline for structural reliability analysis: application to jacket platforms

Rt software. 2013. Department of civil engineering, University of British Columbia (UBC)

Rabi, S. 1991. Offshore structural system reliability under changing load pattern, applied ocean research, Vol.13

Manuel, L. \& Schmucker, D. \& Cornell, C. 1998. A reliabilitybased design format for jacket platforms under wave loads, Marine structure, Vol. 11

SESAM V.7-4. 2015. DNV GL

USFOS V.8-8. 2015. Reality Engineering

Eurocode. 1993. Basis of design and actions on structures

DNV, 1992. Structural reliability analysis of marine structures, Classification note 30.6

MATLAB. R2017a. Mathworks

Fayyazi, A. \& Aghakouchak, A.A. 2014. Calculation of probable extreme wave height during lifetime of offshore platforms in the Persian Gulf, Sea engineering journal 